\title{
Design fiction exploration of romantic interaction with virtual humans in virtual reality ${ }^{1}$
}

\author{
Thommy Eriksson* \\ Chalmers University of Technology, Sweden
}

\begin{abstract}
This article discusses the possibilities and potential issues with romantic and sexual interaction with virtual humans in virtual reality, using the design fiction Into thin air as a starting point for these reflections. Design fiction, a dramatized story by engineers/designers, speculate and critically reflect on advantages and risks with future technology. The primary purpose of the design fiction story utilized in this investigation is to highlight the advantages with air ship traveling (concerning climate impact), but since this was a concept that was difficult to dramatize, I choose to have that as a background setting, and instead foreground a bitter-sweet story about seeking love and sex in different virtual reality simulations during the time onboard an air ship. In most cases these attempts at sexual encounters are with actual women, but in one sequence I bring in the concept of virtual humans.
\end{abstract}

The user wears a full-body haptic feedback suit, so he/she can see, hear and feel the virtual agent. In the design fiction and in this article, I speculate that such virtual agents could be created by including three agents to choose between (automatically generated by algorithms); A) a generic blend of celebrities, B) a recreation of the user's high school love interest, and C) a recreation of a woman the user just had flirted with.

In this article I compare this design fiction scenario with real-life VR applications, trying to explore the feasibility of different virtual human scenarios. Virtual reality developers have so far avoided sexual or romantic content in their experiences, possibly to a large extent because the major distribution platform - Oculus - is controlled by Facebook. Facebook have quite strict regulations concerning what is deemed as appropriate as content, and thus curates the available experiences quite strictly. Some experiences subtly hint at romantic encounters, such as the dating simulators Falling in love and Focus on you. I argue that these two experiences are highly limited and linear. In order to create a more complex and convincing romantic/sexual encounter, the virtual agents would need to be driven by a dialog system and AI. One attempt in that direction is the smartphone app Replika, a chat and voice based virtual agent that tries to give the impression of a caring friend (who can venture into text based sexual encounters).

The conclusion is that it seems likely that the VR dating simulations will gradually evolve and become more convincing, primarily depending on Facebook's control over the market, and the slow but steady progress in dialog systems. The possibility to physically/virtually interact with the beloved virtual agents and have satisfying intercourse seems possible, but not something to expect in the near future.

Link to the design fiction: https://chalmersuniversity.box.com/s/xmoldkihicfxgo6qo4zb2onez45m49fl

Keywords: Virtual reality, dating simulator, design fiction

\section{INTRODUCTION}

The creation of artificial beings has been a dream in human society for a very long time. Mary Shelley's Frankenstein - a modern Prometheus is one of the first, maybe the first, science fiction stories, and its depiction of an artificial human have obviously been followed by countless others. And even before Shelley used science to explain the creation of the monster, there were stories involving magic or god like powers, such as the Galatea and the Golem myths (Austin, 2001; Menon, 2007; Mulvey,

\footnotetext{
${ }^{1}$ Version 4.0; May 31 $3{ }^{\text {st }}, 2021$

*Department of Computer Science and Engineering, Chalmers University of Technology, SE-412 96 Göteborg, Sweden. E-mail: thommy@chalmers.se.

2589-9953 @ 2022 - The authors. Published by IOS Press. This is an Open Access article distributed under the terms of the Creative Commons Attribution-NonCommercial License (CC BY-NC 4.0).
} 
1995). In fiction, these artificial beings are often miserable, and they are often exploited, sexually or in other ways (Haraway, 1991; Springer, 1996). One of the most well-known examples are Rachael, the replicant in Ridley Scott's Blade Runner. Rachael is an artificially created biological human (replicant) with implanted memories, and she meet Deckard, a former police detective hired to hunt down and kill replicants. Racheal is traumatized by her realization that she is not a normal human being, and the romantic relationship she experiences with Deckard is confused and problematic.

As with many other technological dreams and nightmare depicted in science fiction, we are slowly approaching a fulfillment off some of these visions. Robots are becoming more and more technically advanced, and the AI controlling them as well. Researchers and stakeholders with an interest in robots for sexual and romantic experiences see more and more real-life projects to discuss, and not only science fiction scenarios (Cheok, Devlin, \& Levy, 2016). The physical and mechanical challenges in building lifelike and convincingly human-like robots are huge, though. The uncanny valley is wide and very difficult to cross; human-like robots often make people feel uncanny rather than attracted (Brown, 2008; Mori, MacDorman, \& Kageki, 2012). One advantage with the virtual humans that will be discussed in this article is that they can be built and animated without the mechanical and physical challenges and limitations of a hardware robot. Generally, it is technically easier to construct for example life-like facial expressions, and more fluent full body movements, in a virtual character than in a mechanical robot. The relatively wide consumer market adaption of virtual reality headsets promises to be a fertile ground for the development and commercial implementation of virtual humans in different entertainment applications. Is it feasible and preferable that some of these virtual humans will provide sexual and/or romantic experiences? What are the potential obstacles, and what dangers do we need to avoid? Can science fiction narratives and design fiction highlight any potential dangers or opportunities?

\section{BACKGROUND}

\subsection{Virtual humans}

Virtual humans are a quite new field of research and development, and there is a quite diverged terminology: virtual humans, virtual assistants, AI companion, and non-player characters (npc's) are all used in different ways and partially overlapping. What I mean with virtual human in this article is a virtual entity that can be seen and heard either on screen, or via virtual reality or augmented reality. It is resembling a human being, and its behavior (dialog, movements etc.) is controlled by an AI and appears to be human-like.

In computer games it is very common to encounter npc's, but they are usually highly scripted and do not react dynamically to the actions from the player, or at least to a very limited extent. One example of many is the character the player interacts with in the virtual reality game Blade Runner 2049; this character is a human scientist that narrates much of the exposition of the game, explaining the plot.

The feature film Blade Runner 2049 depicts a fictional virtual human, called Joi, and in the context of the film she is a volumetric display with appears to be fully sentient, and who appears to feel love for the main protagonist $\mathrm{K}$ ( $\mathrm{K}$ is much like Deckard mentioned before, a police detective hired to hunt down replicants). Their relationship is primarily platonic since they can't interact physically (with the exception of one scene where a biological woman acts as physical proxy for Joi). Another example from science fiction is the AI operative system in the feature film Her; she is portrayed and presented only by voice, but nevertheless engage in a romantic relationship with the human protagonist. Just 
as in Blade Runner 2049 their relationship is mostly platonic, but here as well is the suggestion of a biological woman being physical proxy.

Considering real-life virtual humans outside of the computer game industry, two of the most advanced prototypes are Mica by Magic Leap and BabyX by Laboratory for Animate Technologies of The University of Auckland. Mica is seen via magic Leap's augmented reality headset and interact so far only with gestures. It is mostly a technology demonstration, but impressive in its seemingly natural behavior and appearances. BabyX is a self-learning AI simulation of a virtual baby. An impressive system of applications creates and controls the interactive behavior of BabyX as well as the rendering of a moving image of its face. The perceived result is a highly convincing and realistic representation of a baby (on screen).

Finally, another interesting real-life example is the AI driving the web application https:// thispersondoesnotexist.com where photorealistic, computer-generated images of humans are automatically created. The images are created by StyleGAN, a self-learning neural network developed by Nvidia. This is an example of how convincing virtual humans could be automatically created based on a set of parameters, thus enabling an endless variety of personalized virtual humans. This stands in stark contrast to the traditional, very labor intensive and skill demanding process of manually $3 \mathrm{~d}$ modeling and programming virtual humans.

\subsection{Virtual reality and dating simulators}

Virtual reality is a media technology where the user puts on a headset covering the eyes and giving the impression of being surrounded by a virtual world that the user can see and hear. There exist different levels of interactivity and immersion, but usually the user can move around in and interact with the virtual world (Sheridan, 1992; Steuer, 1994; Zeltzer, 1992). The hands are tracked so that the user can use natural gestures and direct manipulation of objects. Virtual reality has been available for several decades, but it is not until the last few years that consumer price level headsets have been for sale, and this have sparked a minor but persistent VR hype. The manufacturer Oculus have played a vital role in this development, and it is now owned by Facebook. There are other major manufacturers, such as HTC Vive, but Facebook and Oculus is highly dominant, at least for consumer level virtual reality. Much critique has been raised against Facebook and the potential risk of using virtual reality for surveillance capitalism (Bye, 2020; Zuboff, 2015). As a social media, Facebook have already had extensive issues with leaked user data, incomprehensible user agreements and using large amounts of user data. The fear is that they will use a similar way, and that the sensors of the VR equipment will provide even more sensitive user data. Facebook can store and can potentially use large amount of user data such as usage of experiences, eye gaze (what do you look at and how long in the experience), and your physical environment (their newer headsets use inside-out tracking, meaning that cameras on the headset watch the physical room where you use them). Additionally, in a situation similar to how Apple controls both hardware and software for the iPhone smartphones, Facebook now sells the hardware - virtual reality headsets - that is more or less locked to their Oculus Home distribution platform. In this way, Facebook curates which virtual reality experiences that are available for users. Both of these factors stifle the variation and width of what VR experiences are available for a wide audience. The strict curation limits what is at all available for download and usage. The risk of being surveilled while using potentially embarrassing and/or sensitive experiences could affect many users willingness to use certain experiences, even if they were available.

Dating simulators are game-like applications where the user has interaction with a virtual human, more or less explicitly portraying a romantic and/or sexual encounter (Taylor, 2018). In Japan, these 
dating simulators are highly popular and have been so for may years; these Japanese dating simulators are usually quite unrealistic, and often sexually explicit. In the west, these games have been much less popular, but there are exceptions. A smartphone-based example is Replika, developed by the Russian company Luka. It is marketed as an AI companion and it engages the user with friendly and occasionally romantic dialog. It can be sexually explicit (via text) if the user so chooses. There are also a few virtual reality experiences: Focus on you, Summer Lesson, and Fall in love. Both in Focus on You and Summer Lesson the user encounters a subtly flirtatious teen age schoolgirl, and even if the plot and interaction is a quite simple, scripted branching narrative (using pre-determined dialog choices) creates a basic sense of social presence. These two games have different levels of achievements and takes at least a couple of hours to play. Fall in Love is a much shorter experience where the user interacts with a person for a few minutes. This is also highly scripted via predetermined questions, but recordings of actual actors are used, which gives a quite high level of presence. None of the three virtual reality experiences mentioned is sexually explicit, rather, they are subtly romantic.

\subsection{Innovative technologies and the future of virtual sex}

Another important background for the speculation and reflections made in this article is a mix of different emerging technical solutions.

Volumetric capture is the recording of actors or other performers from different angles and capturing depth data as well. This can then be combined into a $3 \mathrm{~d}$ representation of the actor, so that the viewer can see the actor from different angles, for example walking around the person. This is a quite common method of creating virtual humans in virtual reality experiences (for example the Blade Runner 2049 mentioned above), even if the technology is not fully mature. It is quite difficult to do volumetric recordings, and to achieve good result very expensive studio set-ups are needed. It is possible to use more simple studio set-ups, but the resulting image quality is often quite low. The author and his master thesis students have in two projects explored these simple options, in a dance performance project by director Gorki Glaser-Müller and student Budi Sugianto Jap, and in a technical pipeline project done by student Fausto Ivan Zamora Arias in our research lab Kuggen Medialab. An alternative method is to create a $3 \mathrm{~d}$ model of the virtual human, and then animate this model in different ways, for example using motion capture of an actor. This is time consuming and fully photo-realistic results is still a challenge.

Volumetric capture can essentially be seen as the art of capturing a physical human into a virtual format. The opposite, having a virtual human extend into the actual, physical world would involve haptic suits and teledildonics, at least when it comes to potentially having physical sex with the virtual human. Haptic suits have been experimented with for long, and the goal is to give the sense of touch in the virtual world, for example having an embrace felt as pressure against the upper torso or feeling the brush of fingers against your own fingers. This is a big challenge though, partially because touch is a complex blend of several senses (heat, pressure, limb position etc.). It also involves the whole body, you can almost feel touch anywhere on your body, and this makes it much more complex than senses such as sight and hearing which enters the body on very specific locations (the eyes and ears). Teledildonics is a technology which mimic human sexual interaction, often intended over long distances, but could also potentially be used for giving a virtual human a physical, sexual effect on the user's body. The user could potentially feel the touch of the virtual human. A few attempts at commercial solutions exists, even attempts at combining virtual reality with teledildonics (Locatelli, 2018). Trade journal reports about virtual reality teledildonics suggest that this technology is very immature and have major technical challenges ahead (Merchant, 2014). It can also be assumed that 
(and is suggested by the mentioned trade journals) there is potentially much stigmata towards such technologies, and so far a very limited market potential.

\subsection{Design fiction and science fiction as literary genres}

Design fiction is a design method used to explore the design and implications of future and/or speculative technology (Bleecker, 2009; Coulton, Lindley, Sturdee \& Stead, 2017; Tanenbaum, 2014). It is similar to design scenarios in that it uses narrative to describe users interacting with technology and designed artifacts, but it differs in that it portrays a much more developed world and characters. A design scenario is usually very focused on describing the event of the scenario itself. Design fiction uses a more fully built plot to describe the technology and its role in and impact on society. Design fiction is often critical and reflective. It is very common to write design fiction as a short story, but other formats such as movies, comics, physical artifacts, games and role-playing events are also utilized.

Science fiction is a genre within primarily literature and film, based on the premise of a novum (Suvin, 1979). The novum is a strange or new event or artifact that is inserted into what is otherwise a more or less normal situation, and the implications of the novum is supposed to reveal something about humanity, technology, society or such. Science fiction stories often takes place in the future, because that is one way to insert a novum into the story, but even then it very often criticizes and reflect on the current society. Science fiction is not really about the future, it is about issues here and now, or potential issues. Often the novum is a technology, but it can also be related to politics, society structure, religion or such. Two good examples of the latter are George Orwell's 1984 and Margaret Atwood's A handmaid's tale, telling the story about what happens in a society with ubiquitous surveillance and extreme religious fanatism, respectively.

A common misunderstanding about both design fiction and science fiction is that its purpose is to predict the future. As should be clear from the previous paragraphs, this is not correct. Design fiction and science fiction overlap to some extent, but their purpose is often quite different. Design fiction is often used as a part of a design or development process. Science fiction is usually meant to be entertainment, although with a serious critique or reflection (Määttä, 2010; Russ, 1975).

There is much debate whether science fiction influences technological development (Mubin et al., 2016). It is common to put forward examples of technological artifacts being presented in science fiction, and later being developed for real, such as the computer tablet seen in the space journey epic 2001: A Space Odyssey and the communication devices seen in the different Star Trek TV series. This is essentially a chicken-and-egg problem; there is an iterative loop between real-life technological development and science fiction visions, so that the fantasy is inspired by reality, and reality is inspired by the fantasy.

\section{METHODOLOGY}

As stated in the Background, design fiction is a design method used to explore the design and implications of future and/or speculative technology, and this is how I have used it in this research (Bleecker, 2009; Coulton, Lindley, Sturdee \& Stead, 2017; Tanenbaum, 2014). I choose to write a short story, the most common format, mostly because of the efficiency of production (a movie or a game could have told a similar story in a very interesting way but would have required much more production resources and time). Neither design fiction nor science fiction is primarily about predicting the future, 
and it is important to frame my exploration not as a prediction but as a speculative exploration of possible scenarios, especially their dangers and disadvantages. In a manner, design fiction explorations are similar to the method of cognitive walkthrough used in interaction design (Cooper et al., 2014). When doing a cognitive walkthrough, the designer is systematically thinking through all steps of a process, using questions as a tool to continuously ask what could happen and what the user could do in each situation, and what the consequences would be. Design fiction uses questions in a similar manner (probing what could happen and what the consequences could be) but favor a focus on the emotional impact on the user instead of a systematic exploration of all possibilities.

What is the scientific merit of this study? What is the empirical evidence? Design fiction is a method to speculate on and evolve design concepts and is therefore incorporated under design-based research (Barab \& Squire, 2004; Lindley \& Coulton, 2016). In design-based research the empirical evidence is the process itself and the resulting artifact (Creswell, 2003). When the researcher herself is a part of the process, then the study becomes inherently self-reflective, and from an epistemological perspective the research has similarities with participatory observation, a method commonly used in ethnography (Atkinson and Hammersley, 1989). Ethnography generally denounces the positivistic worldview that the researcher always must be external to the observed system, and instead acknowledge that worthwhile research results can be generated when the observer is an involved in the process (Wall, 2006; Eriksson, 2010). Therefore, the scientific merit of this study is the unique observations made during the process of creating the presented design fiction artifact.

\section{WORK PROCESS}

As described in the previous Methodology section, the work done in this study was the writing of a design fiction short story, and a subsequent reflection.

The original idea for the story is approximately two years old, and I wrote the story itself during two days in the summer of the year 2020 .

The original purpose of the short story was to use it as a scenario for another research area I am pursuing, remote meetings and sustainability. An important factor in the current climate change crisis is of course air travel, and therefore it is important to decrease the amount of air travel, or at least the carbon footprint from these travels. One potential part of the solution could be air ships, which could make cross-ocean travel more sustainable. One issue though is the increased travel time, from hours to days, and my idea for a scenario was that modern remote collaboration technology, especially meetings in virtual reality, could make it possible to work with colleagues and meet with friends and partners while on-route in an air ship. The scenario was that if someone needed to make a long business trip, then the long travel time could be acceptable if shorter everyday meetings could be conducted while traveling.

This is precisely what design fiction can be used for, exploring and illustrating ideas like this. However, many design fictions are quite unengaging stories, primarily because they lack the drama and conflict that usually is used for creating interest and emotional engagement in the reader. The fundamentals of conflict are that a protagonist wants or needs something, and something, often an antagonist, create obstacles (Bordwell, 1985; Genette, 1980). The story then becomes a story about overcoming these obstacles. The conflict can be very explicit - robots from the future tries to kill the protagonist - but they can also be much more subtle and involve emotional and mental obstacles and development. 
I tried for quite some time to come up with a conflict related to the air ship and the remote collaboration that was the initial purpose of the story, but it was difficult to create sufficient emotional relevance. So finally, I shifted the conflict to a more love related theme, and the air ship and the remote collaboration become the setting for the story. For the love related theme, I was highly inspired by the movies Lost in Translation and Her, love stories with a subtly nostalgic mode. Therefore, I constructed a protagonist looking for meaningful love, and introduced the idea of a love affair. I was also deeply inspired by the melancholic and tragic protagonist that is common in several stories by William Gibson, such a Burning Chrome, New Rose Hotel, and The Winter Market. These stories are highly nostalgic or melancholic, depicting characters that are lonely and emotionally traumatized, and lost in a dystopian, technology saturated future.

\section{RESULTS}

The result of the described work process is the short story itself. The full story is available here: https://chalmersuniversity.box.com/s/xmo1dkihicfxgo6qo4zb2onez45m49fl

Below I quote the sections that is most relevant for the reflections I will do in the Discussion section, along with short contextualizing descriptions.

During the protagonists stay at the air ship, two parallel plots play out. In the actual, physical world he meets a woman on the air ship and falls in love with her, but since he already is in a relationship, he doesn't dare to engage with her (the idea being that a high level of surveillance and run-amok usage of social media would make the risk of his fiancé getting to know his infidelity very high). In parallel, his frustrated search for meaningful love results in a series of unsuccessful and unsatisfactory romantic encounters in different virtual, simulated environments. The first one depicted is a dating application, inspired by the swiping gesture interaction of the real-life dating app Tinder, but the gestures here are more visceral: accepting a potential date is done by means of embracing the persons virtual avatar. Rejection is done by shooting the avatar.

"The next day he went for a stroll in that generic European town again, weightless gun in hand. He had embraced a few women, but none had embraced him back. He started to be a bit less quick with that gun. Only 40 women left. Then a woman in red, long hair come around the corner. When he walked towards her with spread out arms, his heart started to beat hard. She was gorgeous. When her avatar slid through him, the street transformed, grew dark. He was being transported. So, she had already embraced him earlier. He was being transported to her environment.

A bedroom. A big bed. Feverishly romantic, laced and pinkish. His heart sank. This wasn't right. It was too good to be true."

What is hinted at and then immediately followed up in the story is that since the users are represented by avatars, it is difficult to know if the person is honest, and it is easy to be scammed. The mentioned tracer program is a software that reveals this.

"She smiled. She moved closer. The tracer program was steadily counting down. He heard her call for him again.

Damned. The user behind the avatar woman was actually a teenage boy in Bangladesh. Fuck. He disconnected all outgoing data, but didn't leave the room. He could after all look at her for a while, until the scammer disconnected him..." 
What follows now is the encounter with a virtual human for a (simulated) causal sexual encounter. This is done in a virtual reality application, and the potential partners he can choose from is automatically generated by an algorithm, some what inspired by the web application https:// thispersondoesnotexist.com/ and the current development of more and more procedural, automatic creation of assets for game development. The three different women was intentionally written to be quite provocative and creepy, to suggest the potential dangers with this technology, as well emphasizing the protagonists lonely and bewildered mental state.

"Afterwards he was so frustrated that he did something he usually never did. The women walking down that European town street were down to a handful, and he didn't want to reach the end of that line. So, he started up a sim instead.

- Welcome, let's build your perfect partner for the night.

Soft-spoken female AI voice, of course.

Three options materialized. He walked up to them, walked around them, let their avatar fill his virtual space, let his body move close to them. The first one was a generic perfect woman, procedurally created based on the latest batch of celebrities. The tag line claimed she was handcrafted, but he simply didn't believe that. There was no soul to her at all. No ghost in the shell, not even a pretend one. The second one was a cheap trick; the avatar was automatically designed to look like his teenage crush from when he was fifteen. He could see it was her, but it didn't really look like her. He knew he could feed the generator a couple of his own photographs of her; he probably had a handful that were not online. But was it worth the effort, and the cost? He talked to her for a few minutes, and completely lost his interest. No way that sim would convince him that it was her, not with that crappy dialog generator. The third one made him angry. It was Dotty. So, the system had noticed their lunch. The emotion interpreters had jumped to conclusions. How could it assume he wanted to go to bed with her, just because they had had lunch and talked for an hour or so?"

Dotty is the actual woman he met on the air ship, and the following sequence emphasized that he thinks it was morally wrong to have sex with the simulated version of Dotty, without her knowledge or consent. The intention is to raise concerns similar to the debate about virtual child pornography as well as ultra-violence in computer games; is all kind of acts acceptable to do against a virtual, non-sentient simulation, or are some acts in themselves morally wrong (Levy, 2002)? (Even if it is not explicitly expressed, I nevertheless assume in the storytelling that these virtual humans, even though apparently behaving like humans, are not sentient or self-aware.)

"He selected Dotty, paid the quite substantial fee. Afterwards he felt so ashamed that he uninstalled the application and went to the observation deck. He fell asleep in one of the deck chairs, awoke in the middle of the night, completely alone."

The story ends with the protagonist's partner breaking up with him, the woman (Dotty) he met on the air ship leaves without saying goodbye, and she blocks him so he can never contact her online.

The story is intentionally ambiguous concerning the protagonists drive and intentions. Is it only sexual desire that attracts him to Dotty, the woman he met on the voyage? What is the purpose of the romantic and sexual interactions in VR? Are they a substitute or a replacement for real-life encounters? There are a couple of reasons for this ambiguity. I think it helps the reader identify with the protagonist. It is common method in storytelling to leave some details vague and open for interpretation, because the reader will then fill that void with her own attitudes and thoughts. I would also argue that it lends realism to the story in the sense that we as humans often do things without really knowing for example whether we are in love or sexually attracted. Finally, by not answering some questions, the reader is 
forced to reflect herself on the issues that is brought up. This is a way to open up an interpretational space of reflection, something which is a common purpose of design fiction.

\section{DISCUSSION}

How feasible is the virtual human for romantic and sexual experiences, depicted in the design fiction?

If we start with the appearance of the virtual human, much progress is done. Volumetric recording can already give a very high level of visual fidelity, and npc's based on $3 \mathrm{~d}$ models generally have high quality in different applications as well. Development of the rendering in game engines such as Unreal Engine promise to enable fully photorealistic virtual humans within a few years. Also, full photorealism is not necessary for a high level of presence, already existing virtual reality applications can offer very high presence without full photorealism. Presence is dependent on other factors such as interaction between user and environment, interaction with others, and immersive aspects such as field of view, frame rate, and resolution.

Continuing with behavior, this is more challenging, especially dialog. The examples discussed earlier in this article are in almost all cases highly scripted, with simple branching narrative. Often the user interacts by choosing given dialog options instead of talking freely. Applications such as Replika and BabyX actually allows free conversations, but they are so far limited in their scope. It seems reasonable that the behavior and dialog of virtual humans will improve, slow but steady. Virtual humans capable of simulating a free dialog around a wide variety of topics seems possible within a few years. (I will not go into a discussion about if and when such virtual humans will actually achieve general intelligence and self-consciousness, instead of just simulating intelligent and self-aware dialog. Such a discussion is outside of the scope of this article.)

As mentioned in the background section, the opportunity to have physical interaction with these virtual humans seems to be a technical bottleneck. As described earlier, it is a mechanical challenge to give a user complex touch sensation on any part of the body. Any conceivable form factors (such as a haptic suit) also is bulky, awkward and clumsy compared to the quick process of slipping on virtual reality headset in front of your eyes and audio headphones over your ears. It seems reasonable to assume that it will take decades until this achieves any technical maturity that could create products interesting for a broader consumer base.

That leads the discussion over to the business aspect of the technology. So far, virtual reality applications have been highly oriented towards quite traditional games (such as Space Pirate Trainer, Beat Saber and Half-Life: Alyx), meeting and teaching applications (such as AltSpace VR and Engage), and virtual study visits and documentary experiences (such as Anne Frank House VR and Chernobyl VR Project). The mentioned dating simulators are few, and they are often depicted as creepy or unethical in trade press. As pointed out by Emily Taylor (2018), the attitudes towards dating simulators are very different between for example Japan (where they are not stigmatized, not even the quite explicit titles) and the US (where even limited erotic content is seen as very problematic). Another important factor is the distribution platforms for virtual reality applications. It is possible to distribute VR experiences as stand-alone applications, but it is difficult for many users to handle this process. The existing ecosystems and marketplaces for virtual reality, primarily Steam and Facebook, make purchase and installation of experiences very simple, and therefore the majority of users use these platforms. The situation is similar to the market dominance that Android (Google) and IOS (Apple) have over smartphone apps. The effect is a very strong procurement of content, and it is highly possible that this will act as a filter for more mature experiences. The risk of surveillance capitalism - for 
example Facebook recording and storing minute details of your interaction in the applications - could also result in a consumer skepticism towards mature content. It is quite reasonable to assume that any risk of having your romantic or sexual interaction with a virtual human accidently becoming public would severely dampen the urge to engage in this activity.

\subsection{Gender issues, male gaze and sex-robots}

Finally, I need to acknowledge that the design fiction story and my analysis of its speculation concerning sex-robots is inherently masculine since that is the position from which I crafted the story and its characters.

Mulvey (1999) coined the concept of the male gaze, meaning an implicit or explicit sexual view of female characters, employed by primarily moviemakers but relevant in all kinds of narrative. It could be argued that my design fiction story has a male gaze, since we as readers take part in the male protagonist's attraction towards both actual and virtual women in the story. As I have pointed out in (Eriksson, 2016), science fiction is disappointing in its lack of normative criticism or feminism views. There are important feminist science fiction writers such as Anne McCaffre, Joanna Russ and Ursula K. Le Guin, but the majority of science fiction authors are men and have a predominantly male view (Kramarae, 1998).

Artificial beings in science fiction stories - physical robots as well as virtual humans - are often female, and often portrayed more or less explicitly as sex slaves. Springer (1996) suggests there is a trend in how male storytellers emphasize the artificially perfect female, but at the same time also have this artificial female reflect a fear of women's liberation. When a female robot is liberated, is it primarily a liberated woman or a liberated robot? Huyssen (1981) also points this out, and specifically address the robot Maria in the dystopic feature film Metropolis. He writes that "as soon as the machine came to be perceived as a demonic, inexplicable threat and as harbinger of chaos and destruction writers began to imagine the Maschinenmensch as woman" (p. 226). The technological, artificial femme fatal described by Springer and Huyssen is prevalent in the writings of William Gibson, and my inspiration from Gibson can be seen. I would agree that I have constructed Dotty and her virtual clone as a femme fatal.

Constructing Dotty as a femme fatal was not intentional, and I can admit it is a trope that might be overused and could have been avoided. However, my inclusion of (virtual) sex-robots in the story was not meant as an approval of that scenario, but rather a reflective critique and invitation to discuss the good as well as the bad effects of such a technology. This is a danger in science fiction, as well as other storytelling, that the authors intention can be misunderstood. The writer of a post-apocalyptic story about a nuclear holocaust is usually not criticized for being pro nuclear weapons, probably because the horrors of nuclear war is obvious for essentially everyone. But Robert Heinlein's Starship Trooper is a good example of a fictional story that have had very different interpretations, ranging from being regarded as fascistic to being praised as an anti-fascist parody (Mendlesohn, 2019). Rubey (1978) makes another illustrative example when he reads the space opera feature film Star Wars as being pro-military while appearing to be anti-war. My intention in writing this design fiction was not to suggest or argue for a total ban of sex-robots, as for example Kathleen Richardson have done (2015), but I tried to construct the narrative so that potential disadvantages with virtual sex-robots would be suggested. At the same time, I didn't want the story to be neither too explicit, nor too closed for different interpretations. I hope a feministic reading of the story is possible, but that is to a large extent up to the reader. 


\section{CONCLUSION}

The conclusion is that it seems likely that virtual reality dating simulations will gradually evolve and become more convincing, both in appearance and behavior, primarily depended on Facebook's control over the ecosystem and the distribution, and the slow but steady progress in dialog systems. The possibility to physically/virtually interact with the beloved virtual agents and have satisfying intercourse seems possible, but not something to expect in the near future.

This suggests that future experiences of interacting with virtual humans will tend to be more romantic then sexual, more implicit then explicit; a kind of virtual "will they or won't they" game. Interestingly, this is very similar to the mostly platonic relationships depicted in the fictional stories Blade Runner 2049 and Her.

\section{REFERENCES}

Atkinson, P. \& Hammersley, M. (1989). Ethnography: Principles in Practice. London: Routledge.

Austin, A. (Frankie Johnny) (2001). Shelley, Gibson, and Hollywood's Love Affair with the Cyborg. Romanticism on the Net. 21. Retrieved from http://www.erudit.org/revue/ron/2001/v/n21/005958ar. html.

Barab, S. \& Squire, K. (2004). Design-based research: Putting a stake in the ground. The Journal of the Learning Sciences, 13(1), 1-14. doi:10.1207/s15327809j1s1301_1.

Bleecker, J. (2009). Design Fiction: A short essay on design, science, fact and fiction. Retrieved from. Bordwell, D. (1985). Narration in the Fiction Film.

Brown, S.T. (2008). Machinic desires: Hans Bellmer's dolls and the technological uncanny in ghost in the shell 2: Innocence. Mechademia, 3, 222-253. doi:10.1353/mec.0.0088.

Bye, K. (2020). Oculus Quest Enthusiasm vs the Skepticism of Bootstrapping VR with Surveillance Capitalism. Voice of VR Podcast. K. Bye.

Cheok, A.D., Devlin, K. \& Levy, D. (2016). Love and sex with robots. In Proceedings for the Second International Conference, Love and Sex with Robots, London.

Cooper, A., Reimann, R., Cronin, D. \& Noessel, C. (2014). About Face 4: The Essentials of Interaction Design. New Jersey: Wiley.

Coulton, P., Lindley, J., Sturdee, M. \& Stead, M. (2017). Design Fiction as World Building. Paper presented at the Research through Design, Edinburgh.

Creswell, J. (2003). A framework for design. In J. Creswell (Ed.), Research Design: Qualitative, Quantitative, and Mixed Methods Approaches. SAGE Publications.

Eriksson, T. (2010). Being native - distance, closeness and doing auto/self-ethnography. ArtMonitor(8).

Eriksson, T. (2016). A Poetics of Virtuality. (PhD). Chalmers University of Technology.

Genette, G. (1980). Narrative Discourse: An Essay in Method. Ithaca, N.Y.: Cornell U.P.

Haraway, D. (1991). A cyborg manifesto: Science, technology, and socialist-feminism in the late twentieth century. In D. Haraway (Ed.), Simians, Cyborgs and Women: The Reinvention of Nature, New York: Routledge. 
Huyssen, A. (1981). The Vamp and the Machine: Technology and Sexuality in Fritz Lang's Metropolis. New German Critique(24/25), 221-237. doi:10.2307/488052.

Kramarae, C. (1998). Feminist fictions of future technology. In S. Jones (Ed.), Cybersociety 2. 0: Revisiting Computer-Mediated Communication and Community. Thousand Oaks. SAGE Publications.

Levy, N. (2002). Virtual child pornography: The eroticization of inequality. Ethics and Information Technology, 4, 319-323. doi:10.1023/A:1021372601566.

Lindley, J. \& Coulton, P. (2016). Pushing the limits of design fiction: The case for fictional research papers. In CHI'16 Proceedings of the 2016 CHI Conference on Human Factors in Computing Systems (pp. 4032-4043).

Locatelli, C. (2018). "The Perfect Companion": From Cyborgs to Gynoids-Sex Robots and The Commodification of Authentic Intimate Experience.

Määttä, J. (2010). Kognitiv marknadsföring: tre definitioner av science fiction. In M. Godhe and J. Ramsten (Eds.), Möjliga världar: tekniken, vetenskapen och science fiction, Stockholm: Carlsson bokförlag.

Mendlesohn, F. (2019). The Pleasant Profession of Robert A. Heinlein: Unbound.

Menon, E. (2007). Virtual realities, techno-aesthetics and metafictions of digital culture. In D. Sutton, S. Brind and R. McKenzie (Eds.), The State of the Real - Aesthetics in the Digital Age, London: I.B. Tauris.

Merchant, B. (2014). The Robot That Makes Virtual Sex Feel Real. Vice. Retrieved from https://www. vice.com/en/article/4x3v39/real-sex-virtual-reality-oculus-rift-tenga.

Mori, M., MacDorman, K.F. \& Kageki, N. (2012). The uncanny valley [from the field]. IEEE Robotics \& Automation Magazine, 19(2), 98-100. doi:10.1109/MRA.2012.2192811.

Mubin, O., Obaid, M., Jordan, P., Alves-Oliveria, P., Eriksson, T., Barendregt, W. et al. (2016). Towards an Agenda for Sci-Fi Inspired HCI Research. Osaka, Japan. Paper presented at the ACE2016.

Mulvey, L. (1995). The myth of pandora: A psychoanalytical approach. In A.T.L. Pietropaolo (Ed.), Feminism in the Cinema. Indiana University Press.

Mulvey, L. (1999). Visual pleasure and narrative cinema. In M.C.L. Braudy (Ed.), Film Theory and Criticism: Introductory Readings, New York: Oxford University Press.

Richardson, K. (2015). The asymmetrical 'relationship': Parallels between prostitution and the development of sex robots. Published on the ACM digital library as a special issue of the ACM SIGCAS newsletter. SIGCAS Computers \& Society, 45(3), 290-293. doi:10.1145/2874239.2874281.

Rubey, D. (1978). Star Wars - Not so Long Ago, Not so Far Away. Jump Cut: A Review of Contemporary Media(18).

Russ, J. (1975). Towards an Aesthetic of Science Fiction. Science Fiction Studies, 2(6).

Sheridan, T. (1992). Musings on Telepresence and Virtual Presence. Presence: Teleoperators and Virtual Environments, 1(1). doi:10.1162/pres.1992.1.1.120.

Springer, C. (1996). Electronic Eros: Bodies and Desire in the Postindustrial Age. Austin: University of Texas Press.

Steuer, J. (1994). Defining virtual reality: Dimensions determining telepresence. In F. Biocca and M. Levy (Eds.), Communication in the Age of Virtual Reality, Hillsdale: Lawrence Erlbaum Associates.

Suvin, D. (1979). Metamorphoses of Science Fiction. New Haven: Yale University Press. 
Tanenbaum, J. (2014). Design fictional interactions: Why HCI should care about stories. Interactions, 21(5), 22-23. doi:10.1145/2648414.

Taylor, E. (2018). Dating Simulation Games - Romance, Love. and Sex in Virtual Japan: Independently Published.

Wall, S. (2006). An Autoethnography on Learning about Autoethnography. International Journal of Qualitative Methods, 5.

Zeltzer, D. (1992). Autonomy, interaction and presence. Presence, 1, 127-132. doi:10.1162/pres. 1992.1.1.127.

Zuboff, S. (2015). Big other: Surveillance capitalism and the prospects of an information civilization. Journal of Information Technology, 30. doi:10.1057/jit.2015.5. 